\title{
SPECTRUM OF LESIONS IN URINARY BLADDER- A HISTOPATHOLOGICAL STUDY
}

Anita Shah, ${ }^{1}$ Manglesh Srivastava, ${ }^{1}$ Ashok Samdurkar, ${ }^{1}$ Ghanshyam Sigdel ${ }^{2}$

\section{ABSTRACT}

\section{INTRODUCTION}

The lesions of urinary bladder both non-neoplastic and neoplastic pose a common source of both morbidity and mortality. An accurate diagnosis of these lesions requires cystoscopy which allows a direct visualization of the bladder mucosa and biopsies of suspected lesions. Urinary bladder cancer is sixth most common cancer worldwide and represents a heterogeneous group of neoplasms. The current study aimed to study the different bladder lesions and its clinical features to detect it in early stage and as a mainstay option in the diagnosis and follow up.

\section{MATERIAL AND METHODS}

This was a retrospective analysis of biopsies of urinary bladder submitted to the department of pathology over a period of 12 months. The study was approved by the institutional review board of the Universal College of Medical Sciences (UCMS-TH). All the urinary bladder biopsies received in the department were included in the study whereas autolysis of specimen and inadequate biopsies were excluded.

\section{RESULTS}

Among the 36 cases of urinary bladder lesions, the majority (35.36\%) were in age group 61-70 years $(22.33 \%)$. The patients had combination of lower urinary tract symptoms, the commonest being hematuria. $30.55 \%$ had non-neoplastic lesions and $69.55 \%$ had neoplastic lesion. Among non- neoplastic cases, 5.55\% had chronic granulomatous inflammation. Most common neoplastic lesions was infiltrating urothelial carcinoma $(n=6)$ followed by non- invasive urothelial neoplasia $(\mathrm{n}=5)$.

\section{CONCLUSION}

A variety of lesions occur in urinary bladder and is commonly encountered by pathologist. Hematuria was commonest symptom and the clinicians investigated these patients further, which led to discovery of the urothelial tumors. Identification of these patients has an important impact on prognosis as well as on therapeutic approach.

KEY WORDS Histopathology, infiltrating urothelial carcinoma, urinary bladder

1. Department of Pathology, Universal College of Medical Sciences- Teaching Hospital, Bhairahawa, Nepal

2. Department of Surgery, Universal College of Medical Sciences- Teaching Hospital, Bhairahawa, Nepal

DOI: https://doi.org/10.3126/jucms.v6i2.22473

\author{
For Correspondence \\ Dr. Anita Shah \\ Department of Pathology \\ Universal College of Medical Sciences \\ Bhairahawa, Nepal \\ Email:anitashah50@yahoo.com
}




\section{INTRODUCTION}

The lesions of urinary bladder including both non neoplastic and neoplastic pose a common disease in the general population and are often disabling. Tumors of the bladder are an important source of both morbidity and mortality. ${ }^{1}$ Amongst bladder tumors, urothelial carcinoma is a common malignant tumor of urinary bladder and comprises of $90 \%$ of primary tumor. ${ }^{2}$ These neoplasms of bladder create biologic, clinical, diagnostic and therapeutic challenges to both urologist and pathologist. ${ }^{2,3}$ Urinary bladder cancer is the sixth most common cancer worldwide and the second most common malignancy of the genitourinary tract after prostate cancer and represents a heterogeneous group of neoplasms. ${ }^{4}$ Bladder neoplasms account for $6 \%$ and $2 \%$ of the cancer incidences in men and women respectively. They are the second most common malignancy which is seen by urologists. ${ }^{5}$ An accurate diagnosis of urinary bladder lesions requires simultaneous data from urology, radiology and surgical pathology labs. Cystoscopy is the primary diagnostic tool for patients who are suspected of having bladder tumors which allows a direct visualization of the bladder mucosa and biopsies of the suspected lesions. ${ }^{6}$ Progress has been made in the field of non-invasive imaging and scientists continue to identify and characterize potential markers or surrogate end points for bladder tumor. Physical examination, cystoscopic evaluation and histopathological analysis of biopsy material are the mainstays of contemporary bladder cancer diagnosis and treatment.

Therefore, we aim to study the different types of bladder lesions and compare them with its clinical features, so as to detect it in early stage and as a mainstay option in the diagnosis and follow up.

\section{MATERIAL AND METHODS}

This study was a retrospective analysis of biopsies of urinary bladder approved by the institutional review board of the Universal College of Medical Sciences (UCMS-TH). The study was carried out in the Department of Pathology, Universal College of Medical Sciences and included all the patients with urinary bladder lesions diagnosed on biopsy who attended the hospital. The study period was $1^{\text {st }}$ of January to $31^{\text {st }}$ of December of the year 2017. Data were collected from pathology archieval. Clinical and cystoscopic findings with the clinical diagnoses of all cases of urinary bladder lesion sent to the laboratory were noted. The material for the study comprised of biopsy from Transurethral Resection of Bladder Tumor (TURBT)/ Bladder biopsy. Inclusion Criteria: All the TURBT biopsies received in the Department of Pathology, Universal College of Medical Sciences. Exclusion Criteria: Autolysed specimen, inadequate biopsies and those with no adequate information were excluded from the study. Inadequate bladder biopsy was defined as that biopsy which could not be interpreted by the pathologist due to an inadequate tissue content or poor preservation. ${ }^{8}$ All the specimen were then fixed in $10 \%$ formalin. The specimens were subjected to standard paraffin embedding and hematoxylin and eosin staining. The specimen was examined in its entirety and the detailed histomorphological examination was done. In each specimen revealing neoplastic pathology, at least 20 fields were examined and grading was done. Then, bladder tumors were studied according to WHO/ISUP (2016) classification. Data was analyzed using Statistical Package for the Social Sciences (SPSS) 21. The main purpose of this study was to determine the clinical features in correlation with histological diagnosis along with frequency of different types of lesions of the urinary bladder.

\section{RESULTS}

A total 1913 biopsies were received in histopathology department of our institution during the study period. Among these, 36 cases were from urinary bladder lesions. A detailed history of each patient regarding age, sex, chief complaints and other relevant findings were obtained from archievals of the Department of Pathology - Universal College of Medical Sciences. In our study, the most common age group was 61-70 years which constituted $35.36 \%$ of total patients followed by $51-60$ years $(22.33 \%)$. The mean age was 52.7 years with male to female ratio of 2.2:1 (Table 1).

Table 1. Distribution of study patients according to Age and gender

\begin{tabular}{|l|l|l|l|}
\hline Age & $\begin{array}{l}\text { Male } \\
\text { n (\%) }\end{array}$ & $\begin{array}{l}\text { Female } \\
\text { n (\%) }\end{array}$ & TotaI \\
\hline$<40$ & $4(11.11)$ & $6(16.7)$ & 10 \\
\hline $41-50$ & $1(2.78)$ & $2(5.55)$ & 03 \\
\hline $51-60$ & $7(19.55)$ & $1(2.78)$ & 08 \\
\hline $61-70$ & $11(30.56)$ & $1(2.78)$ & 12 \\
\hline $71-80$ & $1(2.78)$ & $1(2.78)$ & 02 \\
\hline$>80$ & $1(2.78)$ & 0 & 01 \\
\hline Total & 69.54 & 30.46 & 100 \\
\hline
\end{tabular}

Most of the patient presented with combination of lower urinary tract symptoms, the commonest being hematuria that was seen in $88.66 \%$ patients (Table 2 ).

Table 2. Distribution of study patients according to clinical features

\begin{tabular}{|l|l|l|}
\hline Clinical Features & Frequency & Percent(\%) \\
\hline Bladder exstrophy & 1 & 2.78 \\
\hline Dysuria & 10 & 27.77 \\
\hline Frequency & 16 & 44.44 \\
\hline Hematuria & 32 & 88.66 \\
\hline Urgency & 02 & 5.5 \\
\hline
\end{tabular}

Out of 36 cases included in the study, $30.55 \%(n=11)$ was non 
neoplastic (Figure 1). Among these, most common diagnosis was chronic granulomatous inflammation comprising of $8.34 \%(n=3)$ population (Figure 2$)$.

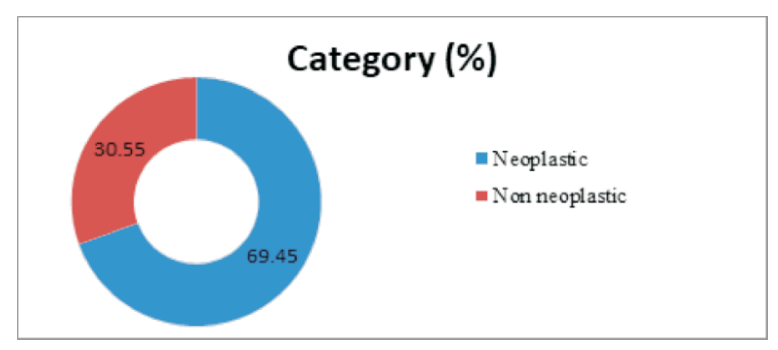

Figure 1. Distribution of study patients according to histologic category

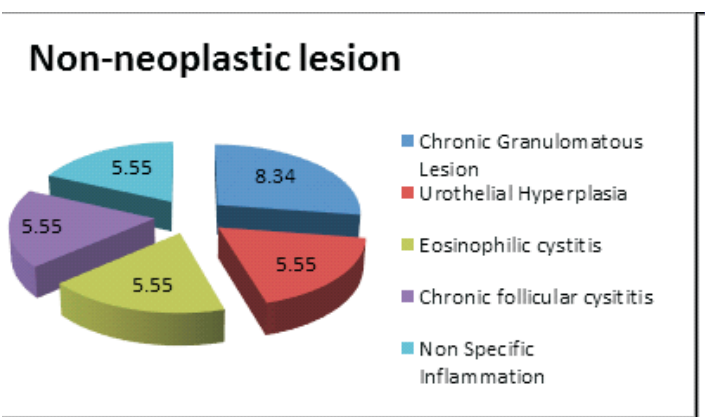

Figure 2. Distribution of study patients according to histopathologic diagnosis of non-neoplastic lesion

Among the neoplastic lesions $(n=25 ; 65.95 \%)$, most common was urothelial tumors comprising of 6 cases of infiltrating urothelial carcinoma followed by 5 cases of non- invasive urothelial neoplasia. The least common amongst the neoplastic lesions was glandular neoplasms comprising of one $(2.78 \%)$ case of papillary adenoma and one case of villous adenoma only (Table 3 ).

Table 3. Distribution of study patients according to histologic category

\begin{tabular}{|l|l|l|}
\hline Histopathological Diagnosis & Frequency & Percent (\%) \\
\hline Infiltrating Urothelial Carcinoma, High grade & 05 & 13.9 \\
\hline Infiltrating Urothelial Carcinoma, Low grade & 01 & 2.78 \\
\hline Non Invasive Urothelial Carcinoma, High grade & 02 & 5.55 \\
\hline Non Invasive Urothelial Carcinoma, Low grade & 03 & 8.34 \\
\hline Urothelial Carcinoma- Cannot exclude Invasion & 01 & 2.78 \\
\hline Carcinoma In Situ & 01 & 2.78 \\
\hline PUNLMP & 02 & 5.55 \\
\hline High Grade Dysplasia & 02 & 5.55 \\
\hline Urothelial Dysplasia & 02 & 5.55 \\
\hline $\begin{array}{l}\text { Urothelial Proliferation of Uncertain Malignant } \\
\text { Potential }\end{array}$ & 01 & 2.78 \\
\hline Inverted Papilloma & 01 & 2.78 \\
\hline Urothelial Atypia & 01 & 2.78 \\
\hline Urothelial Papilloma & 01 & 2.78 \\
\hline Villous Adenoma & 01 & 2.78 \\
\hline Papillary Adenoma & 01 & 2.78 \\
\hline Total & 25 & \\
\hline
\end{tabular}

\section{DISCUSSION}

The present study is undertaken mainly to highlight the importance of histopathological examination in the diagnosis of bladder lesions. In recent days, the diagnosis and monitoring of bladder lesions are made by combination of cystoscopy, histopathology and urine cytology. ${ }^{9}$ All these diagnostic methods have their own limitations and cannot diagnose the presence of bladder tumours at every point of time.

Bladder cancer is the commonest malignancy of the urinary tract, with the incidence being more than two times higher in men than in women (2.2:1). Similar ratio was observed in study done by Hasan et al (2.58:1). ${ }^{11}$ Similar findings were observed by Ploeg et al, ${ }^{12}$ Goyal et $\mathrm{ll}^{13}$ and Vaidya et $\mathrm{al}^{14}$ where the incidence was more in males in comparison to females; however the ratio was slightly higher and was 4:1, 5.25:1 and $5: 1$ respectively.

Most common age group in the present study was 61-70 years with $33 \%$ cases which was correlated with Vaidya et $\mathrm{al}^{14}$ of $33.73 \%$ cases of $61-70$ years while mean age of presentation was 52.7 years which was correlated with study done by Matalka et $\mathrm{al}^{5}$ in which mean age of the patients was 60.6 years . Most of the patients in the present study had constellation of clinical features and most common one was hematuria followed by increased urinary frequency.

Our study showed increased prevalence of invasive urothelial carcinoma than non-invasive urothelial carcinoma which correlated with Vaidya et al $^{14}$ and Christopher et al. ${ }^{15}$ This increased prevalence of high grade urothelial carcinoma in our study may be due to lack of awareness among the people, low socio-economic status and poor hygienic practices among the patients.

Carcinoma in situ is a neoplastic change of the urothelium considered to be a high-grade neoplasm and is an indicator of progression of urothelial neoplasm that requires specific treatment. ${ }^{14}$ In this study, incidence of carcinoma in situ was $2.78 \%$. In contrary, the incidence was $0.62 \%$ in a study done by Vaidya et al. ${ }^{14}$

Papillary urothelial neoplasm of low malignant potential (PUNLMP) was seen in $5.55 \%$. In the study conducted by Shim et $\mathrm{al}^{16}$ and Baidya et al, ${ }^{17}$ PUNLMP cases constituted of $27.3 \%$ and $4.01 \%$ respectively. PUNLMP is a urothelial lesion that biologically carries a low risk of progression according to some studies. Many of these patients had tumor recurrence (upto $60 \%$ ) and they often presented with higher grade tumor recurrence. ${ }^{16,18,19}$ Therefore, it is important to recognize these tumors and alert the clinician for timely treatment. 


\section{CONCLUSION}

A wide variety of interesting lesions are commonly encountered by the general surgical pathologist. Urinary bladder biopsy is one of the most common biopsies in urology practice. In our study, bladder tumors were the commonest lesions seen in cystoscopic biopsies and urothelial carcinoma was the predominant tumor type. Hematuria was a common symptom in our series and the clinicians showed a keen awareness to the dangers of this symptom and investigated these patients further which led to discovery of the urothelial tumors. Identification of these patients has an important impact on prognosis as well as on therapeutic approach.

\section{REFERENCES}

1. Kumar V, Abbas AK, Fausto N. The lower urinary tract and male genital system: Robbins and Cotran pathologic basis of diseases.8th Ed, Saunders, Philadelphia, USA ; 2016 .102636.

2. Rosai J. Rosai and Ackerman's surgical pathology, Mosby. 9th Ed. Edinburgh, 2004: 2892.

3. Hussain N, Shumo I, Mekki S, Dawi N, Elsid S. A clinicopathological study of urinary bladder neoplasms in patients at three centers in Khartoum, Sudan, Sudan Jour of medical science.2009; 4(3): 249-255.

4. Lopez-Beltran A. Bladder cancer: clinical and pathological profile. Scand J Urol Nephrol Suppl 2008. Sep;218 (218):95109

5. Matalka I, Bani- Hani K, Shotar A, Bani Hani O, Bani Hani I. Transitional cell carcinoma of the urinary bladder A clinicopathological study. Singapore Med J. 2008 ;Oct. 49 (10) $: 790-4$

6. Grignon DJ. Urologic Surgical Pathology. St Loius: Mosby. Neoplasm of the urinary bladder, 1997;215-305

7. Stephen J, Jonathan I Epstein et al, Correlation of Cystoscopic Impression with Histologic Diagnosis of Biopsy Specimens of the Bladder. Human Pathology;32:630-637.

8. Ausama SAM, Inconclusive Urinary Bladder Biopsy: Facts and Lessons. The Iraqi Postgraduate Medical Journal 2007;6(4): 303-306

9. Muhammed M, Javed IK, Altaf $\mathrm{H}$ et al. Urinary bladder tumous in southern Pakistan: A histopathological perspective, MJC. 2014; 5 (3): 167-173

10. Reuter VE. The pathology of bladder cancer. Urology. 2006; 67(3 Suppl 1): 11-8

11. Hasan SM, Imtiaz F. Frequency of transitional cell carcinoma in local suburban population of Karachi. JLUMHS 2007; 8385 .
12. Ploeg M, Aben KKH, Kiemeney LA.The present and future burden of Urinary bladder cancer in the world. World J Urol 2009, 27: 289-93

13. Goyal VK, Vyas SP, Kothari DC. Spectrum of Lesions in Urinary bladder Biopsies: Histopathological Study. Int J Dent Med Res 2015; 11(6): 42-6

14. Vaidya S, Lakhey M, KC S, Hirachand S. Urothelial tumors of the urinary bladder: A histopathological study of cystoscopic biopsies. J Nepal Med Assoc 2013; 52(191): 475-8.

15. Christopher HCH, Praveen S, Goh EH. Clinicopathological features of bladder tumours in a single institution in Malaysia Asian Pac J Cancer Prev. 2010;11(1): 149-52

16. Shim, J.W., Cho, K. S., Choi, Y.D., Park, Y.W., Lee, D.W., Han, W. S., Cho N. H. Diagnostic algorithm for papillary urothelial tumors in the urinary bladder. Virchows Archiv; 2008; 452(4), 353-362.

17. Baidya R, Sigdel B, Biadya NL: Histopathological study of cystoscopic bladder biopsies: Journal of Pathology of Nepal ;2015; 5; 717-19

18. Samaratunga H, Makarov DV and Epstein JI. Comparison of WHO/ ISUP and WHO classification of noninvasive papillary urothelial neoplasms for risk of progression. Urology 2016; $202 ; 60: 315$

19. Fujii Y, Kawakami S, Koga F, Nemoto T, Kihara K. Long-term outcome of bladder papillary urothelial neoplasms of low malignant potential. BJU Int 2003;92:559-62 